\title{
Formation of zinc oxalate from zinc white in various oil binding media: the influence of atmospheric carbon dioxide by reaction with ${ }^{13} \mathrm{CO}_{2}$
}

Kim Pilkjær Simonsen ${ }^{1}$, Josephine Niemann Poulsen ${ }^{1}$, Frederik Vanmeert ${ }^{2,3}$, Morten Ryhl-Svendsen ${ }^{1}$, Jesper Bendix ${ }^{4}$, Jana Sanyova ${ }^{3}$, Koen Janssens ${ }^{2}$ and Francisco Mederos-Henry ${ }^{3^{*}}$ (1)

\begin{abstract}
The formation of metal oxalates in paintings has recently gained a great deal of interest within the field of heritage science as several types of oxalate compounds have been identified in oil paintings. The present work investigates the formation of metal oxalates in linseed oil in the presence of the artists' pigments zinc white, calcite, lead white, zinc yellow, chrome yellow, cadmium yellow, cobalt violet, and verdigris. The oil paint films were artificially photo-aged by exposure to UVA light at low and high relative humidity, and afterwards analysed by attenuated total reflectanceFourier transform infrared spectroscopy (ATR-FTIR). The results showed that, compared to the other pigments investigated, zinc white is especially prone to metal oxalate formation and that high humidity is a crucial factor in this process. Consequently, the reactivity and photo-aging of $\mathrm{ZnO}$ in various oil binding media was investigated further under simulated solar radiation and at high relative humidity levels. ATR-FTIR showed that zinc oxalate is formed in all oil binding media while X-ray powder diffraction (PXRD) revealed it was mainly present in an amorphous state. To examine whether atmospheric $\mathrm{CO}_{2(\mathrm{~g})}$ has any influence on the formation of zinc oxalate, experiments with isotopically enriched ${ }^{13} \mathrm{CO}_{2(\mathrm{~g})}$ were performed. Based on ATR-FTIR measurements, neither $\mathrm{Zn}^{13} \mathrm{C}_{2} \mathrm{O}_{4}$ nor $\mathrm{Zn}^{13} \mathrm{CO}_{3}$ were formed which suggests that the carbon source for the oxalate formation is most likely the paint itself (and its oil component) and not the surrounding atmosphere.
\end{abstract}

Keywords: Metal oxalates, Zinc white, Zinc oxalate, Reaction with ${ }^{13} \mathrm{CO}_{2}$, Oil containing binding media

\section{Introduction}

Metal oxalates in oil paintings have recently attracted the attention of heritage scientists as their origin and mechanism of formation has not yet been fully elucidated [1-6]. Results published in the scientific literature suggest that different mechanisms might be involved depending on the artworks' constituent materials and the environmental conditions to which they were exposed. For instance,

\footnotetext{
*Correspondence: francisco.mederos@kikirpa.be

${ }^{3}$ Laboratories of the Royal Institute for Cultural Heritage (KIK-IRPA), Parc du Cinquantenaire 1, 1000 Brussels, Belgium

Full list of author information is available at the end of the article
}

in the case of outdoor wall paintings and monuments constituted of calcareous stone materials, the formation of calcium and copper oxalates has been explained mainly by microbiological activity [7-10], though formation due to applied conservation treatments and atmospheric pollution has also been proposed [11, 12]. For easel (and other weather-protected) paintings the presence of metal oxalates has been attributed to chemical interactions between the pigment and the varnish layer $[5,6,13]$, to reactions between the pigment and oxalic acid present in aerosols [3], or to photodegradation of the binder [4, 14], especially given if the latter has a high lipidic content such as in drying oils and egg tempera [15].
Springer Open

(c) The Author(s) 2020. This article is licensed under a Creative Commons Attribution 4.0 International License, which permits use, sharing adaptation, distribution and reproduction in any medium or format, as long as you give appropriate credit to the original author(s) and the source, provide a link to the Creative Commons licence, and indicate if changes were made. The images or other third party material in this article are included in the article's Creative Commons licence, unless indicated otherwise in a credit line to the material. If material is not included in the article's Creative Commons licence and your intended use is not permitted by statutory regulation or exceeds the permitted use, you will need to obtain permission directly from the copyright holder. To view a copy of this licence, visit http://creativeco mmons.org/licenses/by/4.0/. The Creative Commons Public Domain Dedication waiver (http://creativecommons.org/publicdomain/ zero/1.0/) applies to the data made available in this article, unless otherwise stated in a credit line to the data. 
Indeed, it has been demonstrated that ageing conditions including exposure to ultraviolet (UV) radiation and high humidity, can induce the oxidation of fatty acids and favour the formation of low molecular weight dicarboxylic acids such as oxalic acid $[15,16]$. In such a process, pigments are considered to be one of the possible sources of the metal cations forming the oxalate salt $[17$, 18]. The catalytic role played by certain copper, lead, zinc and chrome-based pigments has also been pointed out $[4,5,16]$.

In any case, not all pigments are prone to oxalate formation in oil paint films. For instance, copper oxalates have commonly been found in oil paint films containing either copper acetate or basic copper chloride pigments, such as in a series of fifteenth century Gothic Catalan paintings [1] or Hans Memling's Christ with Singing and Music-making Angels altarpiece [17]. Nonetheless, they seem to be absent in paint films containing other copper-based pigments such as azurite [18]. Lead oxalate has been found in red areas containing minium $\left(\mathrm{Pb}_{3} \mathrm{O}_{4}\right)$, or in paint layers containing lead-tin yellow [1, 2] while cadmium oxalates have been found associated to cadmium yellow (CdS) in paintings such as Flowers in a blue vase by Vincent van Gogh [13] and in Le bonheur de vivre by Henri Matisse [14]. Zinc oxalate has been found in several nineteenth and twentieth-century oil paintings by Munch or Picasso [3] and by van Gogh [19]. In the above-mentioned paintings, it was proven that zinc oxalate originated from the zinc white pigment, possibly due to this pigment's recognized photoactivity [5]. As for calcium oxalates, the most frequently found metal oxalate in easel paintings $[1,17,18,20]$, the origin of the calcium cation is usually attributed to either calcium-containing materials (e.g. fillers and lake substrates) in the paint and ground layers or from particulate matter such as dirt deposited onto the paint surface $[17,20]$. More recently, the catalytic role of $\mathrm{Cr}(\mathrm{VI})$ metal cations in the formation of calcium oxalate from calcite fillers in chrome yellow oil paints has also been described [4].

Considering the above, the present paper investigates the formation of metal oxalates in linseed oil paint films containing pigments such as zinc white $(\mathrm{ZnO})$, calcite $\left(\mathrm{CaCO}_{3}\right)$, lead white, $\left(\mathrm{Pb}_{3}\left(\mathrm{CO}_{3}\right)_{2}(\mathrm{OH})_{2}\right)$, zinc yellow $\left(\mathrm{KZn}_{2}\left(\mathrm{CrO}_{4}\right)_{2}\left(\mathrm{H}_{2} \mathrm{O}\right)(\mathrm{OH})\right)$, chrome yellow $\left(\mathrm{PbCrO}_{4}\right)$, cadmium yellow (CdS), cobalt violet $\left(\mathrm{Co}_{3}\left(\mathrm{PO}_{4}\right)_{2}\right)$ and verdigris, $\left(\mathrm{Cu}\left(\mathrm{CH}_{3} \mathrm{COO}\right)_{2} \cdot \mathrm{H}_{2} \mathrm{O}\right)$. Also, given it was found that zinc white-based oil films were particularly prone to metal oxalate formation, further investigations using $\mathrm{ZnO}$ dispersed in different oil media were performed. Finally zinc white's capacity to reduce $\mathrm{CO}_{2}(\mathrm{~g})$ into the oxalate anion was tested by exposing $\mathrm{ZnO}$-based oil films to ${ }^{13} \mathrm{C}$ labelled $\mathrm{CO}_{2(\mathrm{~g})}$. Indeed, semiconductor-mediated reduction of $\mathrm{CO}_{2}$ into different carbon-containing species such as oxalates are currently investigated as part of environmental chemistry research [21, 22]. Thus, it was worth investigating the influence of atmospheric $\mathrm{CO}_{2}$ as a possible source of zinc oxalate $(\mathrm{ZnOx})$ in oil paint layers.

\section{Experimental}

\section{Materials}

$\mathrm{Na}_{2}^{13} \mathrm{C}_{2} \mathrm{O}_{4}\left(99\right.$ atom\% ${ }^{13} \mathrm{C}$ ) and ${ }^{13} \mathrm{CO}_{2(\mathrm{~g})}\left(99\right.$ atom $\left.\%{ }^{13} \mathrm{C}\right)$ were obtained from Sigma-Aldrich (Copenhagen, Denmark). Other chemicals including the pigments $\mathrm{ZnO}$, $\mathrm{Pb}_{3}\left(\mathrm{CO}_{3}\right)_{2}(\mathrm{OH})_{3}, \mathrm{CaCO}_{3}, \mathrm{Cu}\left(\mathrm{CH}_{3} \mathrm{COO}\right)_{2} \cdot \mathrm{H}_{2} \mathrm{O}$, and $\mathrm{CdS}$ were of analytical grade and used as received from SigmaAldrich. Zinc yellow, $\mathrm{KZn}_{2}\left(\mathrm{CrO}_{4}\right)_{2}\left(\mathrm{H}_{2} \mathrm{O}\right)(\mathrm{OH})$, was prepared as described in [23], chrome yellow, $\mathrm{PbCrO}_{4}$, and cobalt violet $\mathrm{Co}_{3}\left(\mathrm{PO}_{4}\right)_{2}$ were prepared as described in [24]. All solutions were prepared with deionised water.

Siccative de Haarlem $(1.42 \%(\mathrm{w} / \mathrm{w})$ Co), raw linseed oil, and linseed standoil were obtained from Københavns Farvehandel (Copenhagen, Denmark). Dammar, shellac, and pine colophony were obtained from Kremer Pigmente (Aichstetten, Germany). Tall oil modified alkyd based on isophthalic acid and pentaerythritol was obtained from Dyrup A/S (Copenhagen, Denmark).

\section{Syntheses}

Reference samples of $\mathrm{ZnOx} \cdot 2 \mathrm{H}_{2} \mathrm{O}, \mathrm{PbOx}, \mathrm{CaOx} \cdot 2 \mathrm{H}_{2} \mathrm{O}$, $\mathrm{CdOx} \cdot 3 \mathrm{H}_{2} \mathrm{O}, \mathrm{CuOx}$, and $\mathrm{CoOx} \cdot 2 \mathrm{H}_{2} \mathrm{O}$ were made by salt metathesis reaction in aqueous solution by adding ammonium oxalate monohydrate $(20 \mathrm{mmol}$ in $100 \mathrm{~mL}$, $70{ }^{\circ} \mathrm{C}$ ) to a stirred solution of the metal salt (nitrate or sulphate, $20 \mathrm{mmol}$ in $100 \mathrm{~mL}, 70{ }^{\circ} \mathrm{C}$ ). During addition the desired oxalate salt precipitated. The suspension was allowed to stir for a couple of hours while cooling to ambient temperature. The crystals were then filtered off, washed with $3 \times 15 \mathrm{~mL}$ of cold water and dried in air.

${ }^{13} \mathrm{C}_{2}$ labelled zinc oxalate was prepared by precipitation from aqueous solutions of zinc nitrate and ${ }^{13} \mathrm{C}_{2}$ labelled sodium oxalate dissolved in deionized water as follows: an aqueous solution prepared by dissolving $0.10 \mathrm{~g}$ $(0.74 \mathrm{mmol})$ of $\mathrm{Na}_{2}^{13} \mathrm{C}_{2} \mathrm{O}_{4}$ in $10 \mathrm{~mL}$ of water was dropwise added under stirring to a solution of $0.22 \mathrm{~g}(0.74 \mathrm{mmol})$ of $\mathrm{Zn}\left(\mathrm{NO}_{3}\right)_{2} \cdot 6 \mathrm{H}_{2} \mathrm{O}$ dissolved in $10 \mathrm{~mL}$ of water. During addition white crystals precipitated. The mixture was allowed to stir for $2 \mathrm{~h}$ after which the crystals were filtered off, washed with $3 \times 5 \mathrm{~mL}$ of cold water and dried in air. Yield: $0.12 \mathrm{~g}(86 \%)$ of $\mathrm{Zn}^{13} \mathrm{C}_{2} \mathrm{O}_{4} \cdot 2 \mathrm{H}_{2} \mathrm{O}$.

\section{Paint samples for UVA ageing}

$100 \mu \mathrm{m}$-thick paint films for UVA ageing were applied on glass microscope slides using a Zehntner ZUA 2000 Universal Applicator. The paints were produced by mixing a given amount of each pigment, shown in Table 1, 
Table 1 Mass of the different pigments mixed with $0.45 \mathrm{~g}$ of oil binder and calculated experimental binder to pigment (B/ $P_{\text {exp }}$ ) ratios ensuring equimolar metallic cation $\left(n_{\text {cation }}\right)$ concentrations in the formulated paint films

\begin{tabular}{|c|c|c|c|c|c|c|c|}
\hline Pigment & Formula & $M_{w}(g / m o l)$ & $\begin{array}{l}\mathrm{m}(\mathrm{g}) \text { pigment } \\
\text { in } 0.45 \mathrm{~g} \text { oil }\end{array}$ & $n_{\text {pigment }}(\mathrm{mmol})$ & $n_{\text {cation }}(\mathrm{mmol})$ & $B / P_{\exp }$ & $B / P_{\text {ref }}[24]$ \\
\hline Zinc white & $\mathrm{ZnO}$ & 81.4 & 0.49 & 6.0 & 6.0 & 92 & 30 \\
\hline Lead white & $2 \mathrm{PbCO}_{3} \cdot \mathrm{Pb}(\mathrm{OH})_{2}$ & 775.6 & 1.55 & 2.0 & 6.0 & 29 & $10-15$ \\
\hline Calcite & $\mathrm{CaCO}_{3}$ & 100.1 & 0.60 & 6.0 & 6.0 & 75 & - \\
\hline Cobalt violet & $\mathrm{CO}_{3}\left(\mathrm{PO}_{4}\right)_{2}$ & 366.7 & 0.73 & 2.0 & 6.0 & 61 & $20-25$ \\
\hline Verdigris & $\mathrm{Cu}\left(\mathrm{CH}_{3} \mathrm{COO}\right)_{2} \cdot \mathrm{H}_{2} \mathrm{O}$ & 199.7 & 1.20 & 6.0 & 6.0 & 38 & - \\
\hline Cadmium yellow & $\mathrm{CdS}$ & 144.5 & 0.87 & 6.0 & 6.0 & 52 & 30 \\
\hline Chrome yellow & $\mathrm{PbCrO}_{4}$ & 323.2 & 1.94 & 6.0 & 6.0 & 23 & 20 \\
\hline Zinc yellow & $\mathrm{KZn}_{2}\left(\mathrm{CrO}_{4}\right)_{2}\left(\mathrm{H}_{3} \mathrm{O}_{2}\right)$ & 436.9 & 0.87 & 2.0 & 6.0 & 52 & $25-30$ \\
\hline
\end{tabular}

Reference binder to pigment $\left(\mathrm{B} / \mathrm{P}_{\text {ref }}\right)$ values are given for comparison

with $0.45 \mathrm{~g}$ of binding medium (raw linseed oil with $5 \%(w / w)$ of Siccative de Haarlem). In order to ensure that all paint films had an equimolar amount of metallic cations $\left(n_{\text {cation }}\right)$, the binder to pigment ratios $(\mathrm{B} / \mathrm{P})$ were calculated based on that of $\mathrm{PbCrO}_{4}(\mathrm{~B} / \mathrm{P}=20$, e.g. $20 \mathrm{~g}$ of oil to $100 \mathrm{~g}$ of pigment). The calculated $\mathrm{B} / \mathrm{P}$ and $n_{\text {cation }}$ values are also shown in Table 1 . It must be noted that by standardising the molar concentrations of metal ions in the paint samples, the calculated $B / P$ values $\left(B / P_{\text {exp }}\right)$ vary to differing degrees from those typically used in reference paint formulations $\left(\mathrm{B} / \mathrm{P}_{\text {ref }}\right)$. The samples were dried in the dark in a fume hood for 1 month before artificial ageing.

\section{UVA light ageing}

Experiments with UVA light were performed in a lightcuring oven (Egger EL 1 plus $\mathrm{N}_{2}$ ) using compact UVA fluorescent lamps (Osram Blue UVA 9W/76) with radiation wavelengths from 350 to $400 \mathrm{~nm}$. Six lamps were used, four at the top and two at the sides. The measured UVA intensity was $160,000 \mu \mathrm{W} /$ lumen $\left(160 \mathrm{~W} / \mathrm{m}^{2}\right)$ while the measured temperature $\left(\mathrm{T}=28^{\circ} \mathrm{C}\right)$ was caused by the fluorescent lamps. The paint samples were then subjected to a repeating cycle of UVA exposure in the Egger box followed by elevated relative humidity exposure in a desiccator containing water. The $\mathrm{RH}$ is expected to be around $100 \%$ in the desiccator and low in the Egger box due to the fluorescent lamps. The time intervals are shown in Table 2 .

\section{ZnO samples in various oil binders}

In these experiments, the $\mathrm{B} / \mathrm{P}$ ratio for $\mathrm{ZnO}$ in the various oil binding media was 30 in accordance with its reported value for linseed oil [24]. The different binding media used were: (a) raw linseed oil, (b) raw linseed oil with $5 \%(\mathrm{w} / \mathrm{w})$ of Siccative de Haarlem, (c) standoil, (d) tall oil modified alkyd, and standoil mixed with an equivalent mass of $10 \%(\mathrm{w} / \mathrm{w})$ solution of: (e) dammar in mineral

\begin{tabular}{|c|c|c|c|}
\hline Reaction & Time (h) & $\Sigma$ UVA & $\Sigma$ Desiccator \\
\hline UVA & 50 & 50 & \\
\hline UVA & 174 & 224 & \\
\hline Desiccator & 408 & & 408 \\
\hline UVA & 166 & 390 & \\
\hline Desiccator & 72 & & 480 \\
\hline UVA & 70 & 460 & \\
\hline Desiccator & 432 & & 912 \\
\hline UVA & 100 & 560 & \\
\hline Desiccator & 72 & & 984 \\
\hline UVA & 92 & 652 & \\
\hline Desiccator & 96 & & 1080 \\
\hline UVA & 74 & 726 & \\
\hline$\Sigma_{\text {TOTAL }}$ & & 726 & 1080 \\
\hline
\end{tabular}

Accumulated reaction time after each UVA or desiccator cycle is given in the corresponding $\Sigma$ columns. Total reaction time is shown as $\Sigma_{\text {TOTAL }}$

turpentine, (f) shellac in ethanol, and (g) pine colophony in ethanol. $100 \mu \mathrm{m}$-thick paint films were applied on melinex polyester films using a Zehntner ZUA 2000 Universal Applicator. All samples were dried in the dark in a fume hood for 1 month before ageing. It is worth noting that, to determine whether the presence of a siccative affects oxalate formation, linseed oil paint films with and without drier were made.

\section{Daylight equivalent ageing of $\mathrm{ZnO}$ in various oil binders} Experiments for artificial sunlight ageing were performed in an Atlas Weather-O-Meter Ci3000 fitted with a $4500 \mathrm{~W}$ water-cooled xenon arc lamp having combined borosilicate soda-lime glass and coated with infrared absorbing outer filter (CIRA) suppressing radiation below $300 \mathrm{~nm}$. The light intensity was 120,000 lx with a 
radiation strength at $80 \mathrm{~W} / \mathrm{m}^{2}(300-400 \mathrm{~nm})$ and $800 \mathrm{~W} /$ $\mathrm{m}^{2}(400-800 \mathrm{~nm})$. The light ageing was performed for $300 \mathrm{~h}$ at $\mathrm{RH}=80 \%$. The measured temperature interval, $\mathrm{T}=35-39^{\circ} \mathrm{C}$, was caused by the xenon arc lamp and was not a chosen parameter.

\section{Ageing in ${ }^{13} \mathrm{CO}_{2}$ atmosphere}

Light ageing experiments in ${ }^{13} \mathrm{CO}_{2(\mathrm{~g})}$ enriched atmosphere were performed at concentrations of 4 and $40 \%$ (v/v) of ${ }^{13} \mathrm{CO}_{2(\mathrm{~g})}$ in the Weather-O-Meter and in UVA light $(40 \%(\mathrm{v} / \mathrm{v}))$. The light ageing was performed for $500 \mathrm{~h}$ for all trials. The samples were placed in a gas-tight container made from tubular ESCAL ${ }^{\mathrm{TM}} \mathrm{Neo}$ gas-barrier film, a heat-sealable polyester film coated with transparent ceramic (Mitsubishi Gas Chemicals). The container was fitted with a $2 \mathrm{~mm}$ quartz glass window $(10 \times 15 \mathrm{~cm})$, which was attached over a hole cut in the gas-barrier film using a double (side by side) bonding with epoxy and silicone glue. The samples of $\mathrm{ZnO}$ paint applied on glass microscope slides were placed inside the bag and held in place by double-sided adhesive tape. The volume of the bag was $400 \mathrm{~mL}$ and the concentration of ${ }^{13} \mathrm{CO}_{2(\mathrm{~g})}$ were obtained by injecting ${ }^{13} \mathrm{CO}_{2(\mathrm{~g})}$ with a glass gas syringe via an inserted needle after which the bag was heat sealed. High RH measured to vary between 70 and $80 \%$ was obtained by placing water drops in the plastic bag. The $\mathrm{ZnO}$ paint samples had a thickness of $100 \mu \mathrm{m}, \mathrm{B} / \mathrm{P}=30$, (raw linseed oil with 5\% (w/w) Siccative de Haarlem), and were dried in the dark in a fume hood for 1 month before ageing.

\section{ATR-FTIR}

ATR-FTIR spectra were recorded on a Perkin Elmer Spectrum One FTIR-spectrometer, fitted with a Universal ATR sampling accessory having a one-bounce composite zinc selenide and diamond crystal. Spectra of the samples were recorded over the range $4000-650 \mathrm{~cm}^{-1}$ with a resolution of $4 \mathrm{~cm}^{-1}$ and 4 accumulations.

\section{PXRD}

Powder XRD analyses were performed with a Bruker D8 Advance diffractometer using Ni-filtered $\mathrm{Cu}-\mathrm{K} \alpha$ radiation $(\lambda=1.54056 \AA)$ and Lynxeye position sensitive detector in the range $2 \theta=5^{\circ}-80^{\circ}\left(\Delta 2 \theta=0.01^{\circ}\right)$ and total exposure time of $8 \mathrm{~h}$. The oil film material was deposited directly on the Si monocrystal zero-background plate and measured at ambient temperature.

\section{$\mu$-PXRD}

$\mu$-PXRD analyses were performed using a low power $\mathrm{I} \mu \mathrm{S}-\mathrm{Cu}^{\mathrm{HB}}$ monochromatic $\mathrm{X}$-ray source $(\mathrm{Cu}-\mathrm{K} \alpha$ radiation, Incoatec $\mathrm{GmbH}$ ) and a PILATUS $200 \mathrm{~K}$ area detector (Dectris Ltd.) positioned in a reflection geometry. The
$\mathrm{X}$-ray source had an incident angle of $12^{\circ}$ with respect to the sample resulting in a beam footprint on the sample of around $0.15 \times 0.8 \mathrm{~mm}^{2}$. Diffraction signals were collected in the range of $2 \theta=12^{\circ}-53^{\circ}$. By moving the X-ray beam over the sample, areas between $0.5-4 \mathrm{~cm}^{2}$ were analysed in a point-by-point manner with a dwell time of $100 \mathrm{~s}$ in each point, for a total period of 4-12 h. Averaged diffraction patterns were calculated from subsets of these areas to improve signal-to-noise ratio. The oil film material was measured either directly on a Si monocrystal zero-background plate or on a melinex polyester film $(100 \mu \mathrm{m})$. The latter allowed analysing the $\mathrm{ZnO}$ oil film from both the top (exposed) and the bottom (unexposed) side. Azimuthal integration was performed using XRDUA [25]. Phase identification was performed using Qualx2 software [26] combined with the crystallography open database (June 2019) [27].

\section{Results and discussion UVA light ageing of various pigments}

ATR-FTIR measurement of the surface of the various pigment samples exposed to UVA light showed no sign of oxalate formation after 50 and $224 \mathrm{~h}$. The spectra for all samples were very similar to the spectrum of the dried sample before treatment. The samples were then placed in a desiccator with water for 17 days in order investigate the influence of the relative humidity after which their IR spectra were recorded again. For $\mathrm{ZnO}$ the changes in the IR spectrum were remarkable whereas the spectra of the other pigments were only slightly affected.

The spectrum of zinc white showed both an increase in the amount of zinc carboxylate (zinc soap) and distinct sign of zinc oxalate ( $\mathrm{ZnOx}$ ) formation (Fig. 1e), which further increased by additional exposure ( 7 days) to UVA (Fig. 1f). In Fig. 1 the evolution of the $\mathrm{ZnO}$ spectra as a function of UVA-RH treatment (in hours) is shown together with the reference spectrum for $\mathrm{ZnOx} \cdot 2 \mathrm{H}_{2} \mathrm{O}$.

As indicated by the arrows, the presence of crystal water $v(\mathrm{O}-\mathrm{H})=3359 \mathrm{~cm}^{-1}$, the symmetrical $\mathrm{C}-\mathrm{O}$ stretches $v(\mathrm{C}-\mathrm{O})=1362$ and $1315 \mathrm{~cm}^{-1}$, and the $\mathrm{C}-\mathrm{C}$ stretch $v(\mathrm{C}-\mathrm{C})=818 \mathrm{~cm}^{-1}$ [3] are clearly seen. The strong asymmetrical $\mathrm{C}-\mathrm{O}$ stretch $v(\mathrm{C}-\mathrm{O})=1621 \mathrm{~cm}^{-1}$ [3] is visible as a shoulder in the absorption region (1700-1500 $\left.\mathrm{cm}^{-1}\right)$ for zinc soaps [28, 29]. The small peak at $1315 \mathrm{~cm}^{-1}$ observed in the spectrum of dried $\mathrm{ZnO}$ (Fig. 1b) may indicate that a minor amount of zinc oxalate is formed together with the zinc soaps while drying of the oil. Likewise, the intensity of characteristic oil binder frequencies (e.g. $\mathrm{C}-\mathrm{H}$ stretches $\left(3000-2800 \mathrm{~cm}^{-1}\right.$ ), $\mathrm{C}=\mathrm{O}$ stretches $\left(1750-1730 \mathrm{~cm}^{-1}\right), \mathrm{C}-\mathrm{O}$ stretches (1200-1100 $\mathrm{cm}^{-1}$ ) and the dominant alkyd peak around $1270 \mathrm{~cm}^{-1}$ ) tend to decrease or disappear as the exposure time to the UVA-RH cycles increases. 


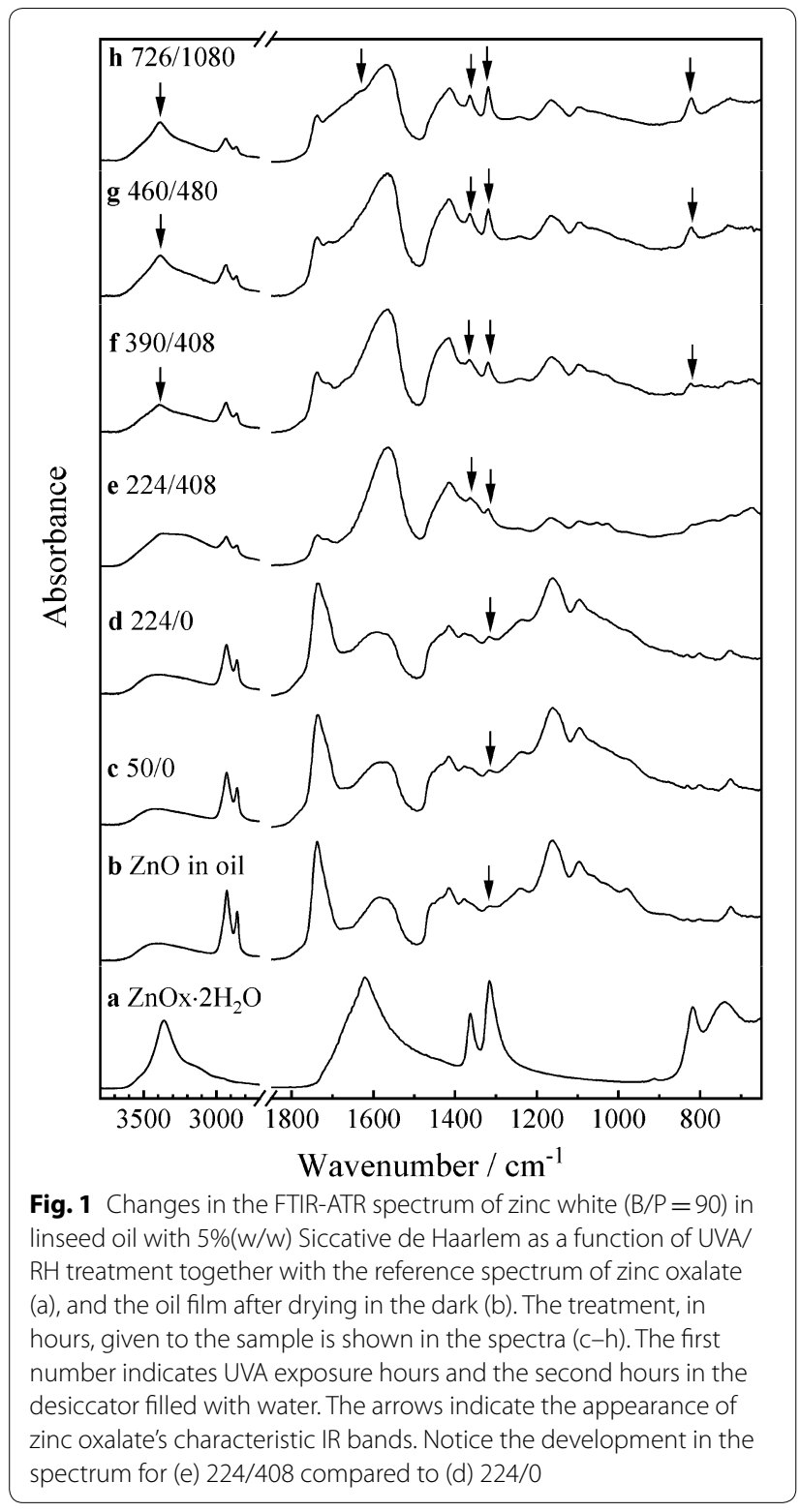

The IR spectra of the other paint films after the final UVA-RH treatment (726/1080 h) are shown in Fig. 2(top) together with the dried oil film before treatment (middle), and the relevant metal oxalate (bottom). As indicated by the arrows a minor amount of metal oxalate may be observed in the spectra of calcite, zinc yellow, and of cobalt violet.

The minor amount of zinc oxalate observed in the spectrum of zinc yellow (Fig. 2c) may be due to the oxidative nature of the chromate ion. The colour of the aged sample showed a distinct greenish hue indicating the presence of $\mathrm{Cr}$ (III). In oil medium, the reduction of $\mathrm{Cr}$ (VI) to $\mathrm{Cr}$ (III) via the chromate $(\mathrm{V})$ species has been well described $[4$,
$30,31]$, and oxidation of oxalate precursors $\left(\mathrm{CO}_{2}^{*}, \mathrm{CO}_{3}^{-\cdot}\right)$ may lower the amount of oxalate ions formed. However, whether chromate ions increase or decrease the formation of oxalate is still unclear.

Figure 2c also shows the clear formation of zinc soap $[28,29]$ indicating the reactive nature of zinc yellow with respect to hydrolysis and reaction with the oil medium. This is likely caused by the presence of hydroxide in the pigment, which structure has been recently solved as $\mathrm{KZn}_{2}\left(\mathrm{CrO}_{4}\right)_{2}\left(\mathrm{H}_{2} \mathrm{O}\right)(\mathrm{OH})$ [23]. The reaction between zinc yellow and the oil medium is in contrast to chrome yellow which colour remained almost unchanged after ageing. The IR spectrum showed no sign of lead oxalate and only a slight presence of lead soap (Additional file 1: Fig. S1). The difference between the two chromate pigments is likely due to zinc yellow's higher solubility and to its hydroxide content, making this pigment the most reactive among the chromate pigments $[23,30]$.

Cobalt violet seems also relatively inert with respect to oxalate formation though a minor amount of cobalt oxalate seems to be present. To our knowledge cobalt oxalate has yet to be found in oil paintings.

Neither lead white, chrome yellow, cadmium yellow or verdigris show sign of metal oxalate formation based on FTIR-ATR spectroscopy (vide supra). However, the presence of carbonate in lead white may impair the detection of lead oxalate's symmetrical $\mathrm{C}-\mathrm{O}$ stretches. Likewise, the amount of metal soap on the surface of the lead white oil film seems comparatively less than for zinc white as indicated by the relative intensity of their characteristic IR vibrations. This result thus suggests a much slower reaction of lead white with the oil binding medium despite its basic nature. Cadmium [13, 14] and copper [1, $15,17,19]$ oxalates have been observed in different paintings, but were not found in this experimental setup or may have formed only in concentrations falling below the detection limit of the ATR-FTIR apparatus.

\section{Daylight equivalent ageing of $\mathrm{ZnO}$ in various oil binding media}

Due to the clear formation of zinc oxalate in the UVA$\mathrm{RH}$ treatment, ageing experiments with zinc white were performed with artificial sunlight (Weather-O-Meter) in various oil binders and in standoil with natural resins $(\mathrm{B} / \mathrm{P}=30)$. The IR spectra after $300 \mathrm{~h}(\mathrm{RH}=80 \%)$ are shown in Figs. 3 and 4 together with the reference spectra of the dried oil films before treatment and that of zinc oxalate.

For the four oil media without resin the IR spectrum could be measured both at the surface and at the backside of the oil film. As seen in Fig. 3, zinc oxalate was formed in all samples. Based on the intensity of characteristic 


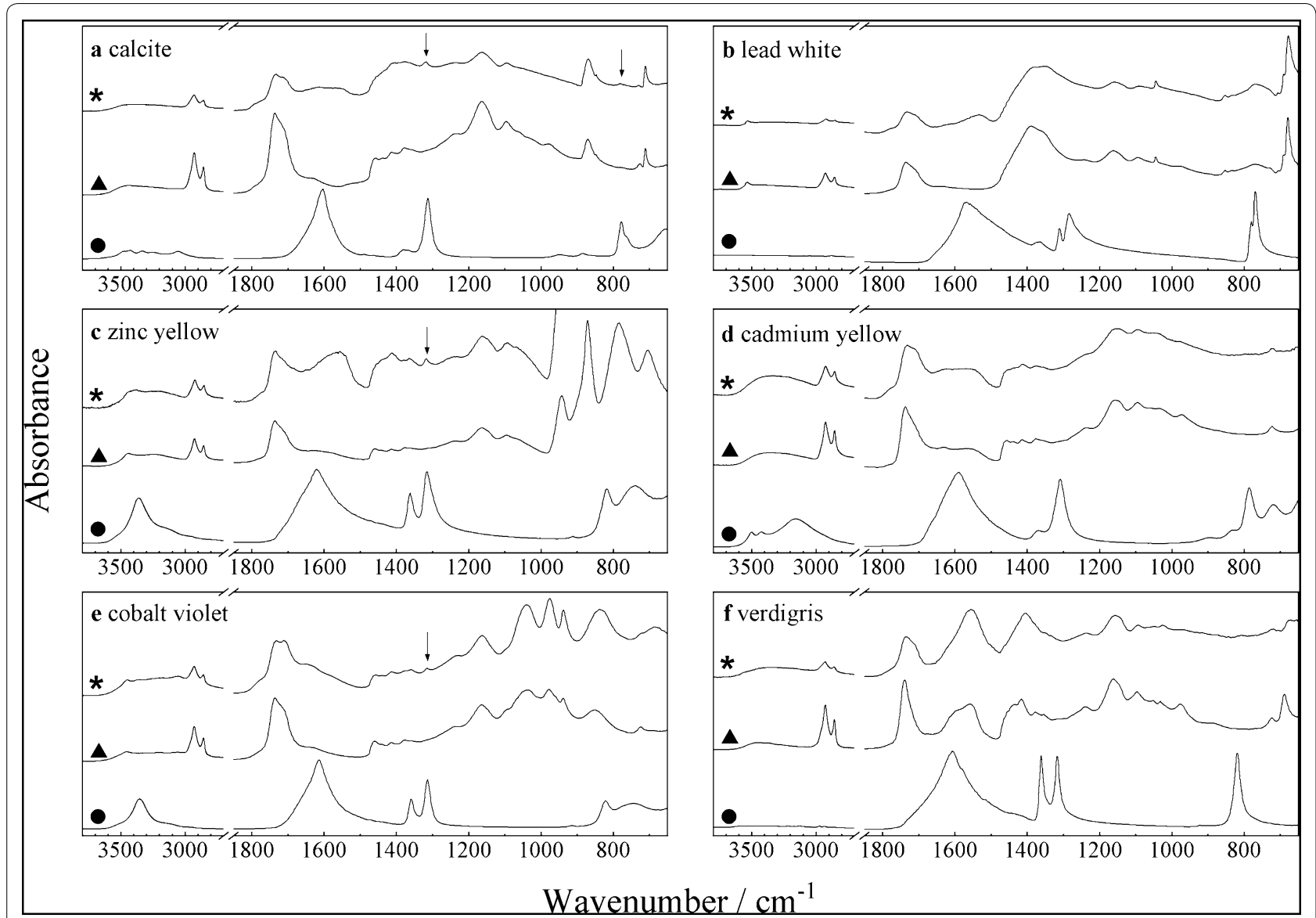

Fig. 2 FTIR-ATR spectra (asterisk) of six pigments (a-f) in linseed oil with 5\% (w/w) Siccative de Haarlem after treatment with UVA for $726 \mathrm{~h}$ and placement in desiccator filled with water for $1080 \mathrm{~h}$. Arrows indicate the presence of characteristic metal oxalate IR bands. Reference spectra of the oil film before treatment (black triangle) and of the corresponding metal oxalates (black circle) are also shown for each pigment. The B/P ratios are given in Table 1

ZnOx IR absorption bands, the amount seems higher at the surface compared to the backside. This notable difference also matches the disappearance of the characteristic oil binder frequencies at the exposed surfaces as shown in Fig. 3d (e.g. C-H stretches $\left(3000-2800 \mathrm{~cm}^{-1}\right)$, $\mathrm{C}=\mathrm{O}$ stretches $\left(1750-1730 \mathrm{~cm}^{-1}\right), \mathrm{C}-\mathrm{O}$ stretches (1200-1100 $\left.\mathrm{cm}^{-1}\right)$ and the dominant alkyd peak around $\left.1270 \mathrm{~cm}^{-1}\right)$. However, in pure linseed oil the amount of $\mathrm{ZnOx}$ and the disappearance of frequencies of the binder appears to be similar on both sides.

The paint film with natural resins in standoil became brittle and crumbly after treatment and only surface measurements were possible. As seen in Fig. 4, zinc oxalate was formed in all samples. Based on the intensity of the $\mathrm{C}-\mathrm{O}$ stretches around 1362 and $1315 \mathrm{~cm}^{-1}$ [3] the relative amount of $\mathrm{ZnOx}$ seems highest in the dammar containing paint film and lowest in the sample containing shellac. However, given the resins were dissolved in different solvents, variable solvent evaporation rates might have caused film inhomogeneities [32]. Therefore, it is difficult to draw a conclusion whether the resins have different or any effect on oxalate formation. Nonetheless, our results clearly demonstrate that all the oil binding media, during exposure to light and humidity, react with zinc white to form zinc oxalate.

\section{Ageing in ${ }^{13} \mathrm{CO}_{2}$ atmosphere}

In order to investigate if atmospheric $\mathrm{CO}_{2(\mathrm{~g})}$ has any influence on the formation of $\mathrm{ZnOx}$, experiments were performed with ${ }^{13} \mathrm{C}$ labelled $\mathrm{CO}_{2(\mathrm{~g})}$. The IR spectrum after exposure for $500 \mathrm{~h}$ in the Weather-O-Meter to a $40 \%(\mathrm{v} / \mathrm{v}){ }^{13} \mathrm{CO}_{2(\mathrm{~g})}$ atmosphere is shown in Fig. 5 together with the reference spectra of zinc white in oil, $\mathrm{Zn}^{13} \mathrm{C}_{2} \mathrm{O}_{4} \cdot 2 \mathrm{H}_{2} \mathrm{O}$, and $\mathrm{Zn}^{12} \mathrm{C}_{2} \mathrm{O}_{4} \cdot 2 \mathrm{H}_{2} \mathrm{O}$. Based on the intensity of the $\mathrm{ZnOx}$ absorption bands, significantly less zinc oxalate appears to have been formed compared to the spectra shown in Fig. 3b (top), even though the reaction time was considerably longer. Characteristic 


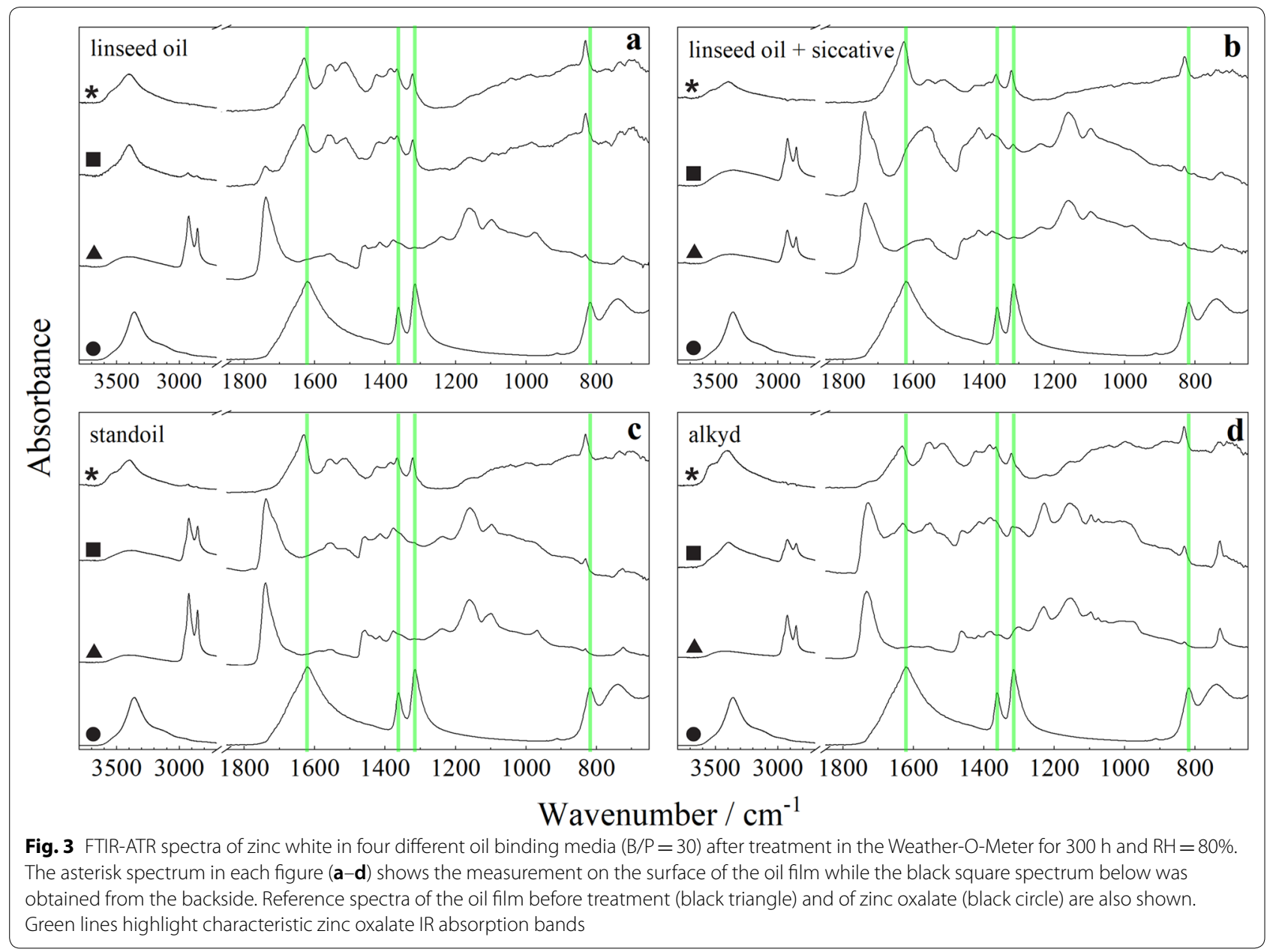

vibrations of the binding medium (e.g. $\mathrm{C}-\mathrm{H}$ and $\mathrm{C}=\mathrm{O}$ ) are also still present. However, the $\mathrm{COO}^{-}$band (1600$1500 \mathrm{~cm}^{-1}$ ), due to zinc soap formation, is dominant showing that reaction between $\mathrm{ZnO}$ and the binding medium has taken place. The lower tendency to form zinc oxalate may be attributed to a decrease in effective light intensity due to the quartz window and the plastic bag. Reaction at $4 \%(\mathrm{v} / \mathrm{v})$ and $40 \%(\mathrm{v} / \mathrm{v}){ }^{13} \mathrm{CO}_{2}$ in UVA light resulted in similar FTIR-ATR spectra.

As expected from the slightly larger mass of ${ }^{13} \mathrm{C}$, the vibrations of the ${ }^{13} \mathrm{C}$ marked oxalate ion appears at lower wavenumbers than that of the ${ }^{12} \mathrm{C}$-containing oxalate [33]. As shown in Fig. 5, the $\mathrm{C}-\mathrm{O}$ stretches appear at 1364 and $1319 \mathrm{~cm}^{-1}$, which is similar to the positions observed in Fig. 1 (1364 and $1319 \mathrm{~cm}^{-1}$ ) and Fig. 2b (1364 and $1320 \mathrm{~cm}^{-1}$ ). Comparison to the reference spectra of $\mathrm{Zn}^{12} \mathrm{C}_{2} \mathrm{O}_{4} \cdot 2 \mathrm{H}_{2} \mathrm{O}$ and $\mathrm{Zn}^{13} \mathrm{C}_{2} \mathrm{O}_{4} \cdot 2 \mathrm{H}_{2} \mathrm{O}$ also confirms the presence of the ${ }^{12} \mathrm{C}$-containing oxalate ion while no characteristic absorption bands for ${ }^{13} \mathrm{C}_{2} \mathrm{O}_{4}{ }^{2-}$ are observed. These results indicate that either no zinc ${ }^{13} \mathrm{C}$-oxalate is formed or only at concentrations falling below the technique's limit of detection.

Based on these IR investigations it appears that the formation of zinc oxalates follows the formation of zinc soaps which recently has been shown to be present as ionomeric clusters [34-38]. We believe that these clusters could be the precursors for the formation of zinc oxalates by bond breaking and oxidation of the long chain fatty acids through a radical mechanism, the radicals possibly being caused by light absorption/photoactivity of $\mathrm{ZnO}$. The lack of increased $\mathrm{Zn}^{13} \mathrm{C}_{2} \mathrm{O}_{4} \cdot 2 \mathrm{H}_{2} \mathrm{O}$ formation as a function of increased ${ }^{13} \mathrm{CO}_{2(\mathrm{~g})}$ concentration further suggests that oxalate formation originates from carbon sources in the oil and not from atmospheric ones such as $\mathrm{CO}_{2(\mathrm{~g})}$. Based on our results, we consider it very unlikely that atmospheric carbon dioxide plays any role in the oxalate formation. Hence, the oxalate ions formed are not due to a reductive mechanism that might involve the reduction of $\mathrm{CO}_{2}$ $[21,22]$ but rather originate from the oxidation of the oil binder. 


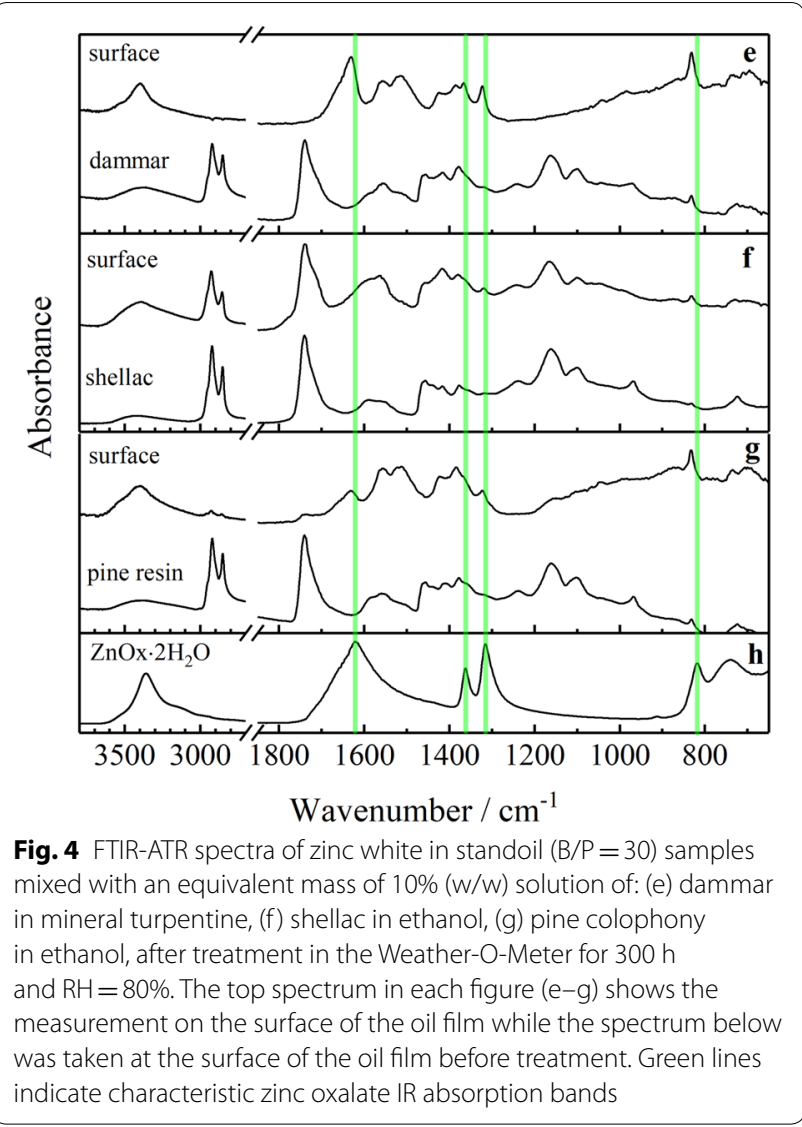

\section{PXRD characterization}

In order to investigate the crystallinity of the formed zinc oxalate, PXRD was performed on the pure linseed oil paint film which showed the largest amount of $\mathrm{ZnOx}$ based on the IR spectrum (Fig. 3a). The diffractogram of $\mathrm{ZnO}$ in linseed oil after treatment for $300 \mathrm{~h}$ is shown in Fig. 6 together with a close-up of the diffractogram. Also shown are reference diffractograms for $\mathrm{ZnC}_{2} \mathrm{O}_{4} \cdot 2 \mathrm{H}_{2} \mathrm{O}$, $\mathrm{ZnO}$, and various concentrations of $\mathrm{ZnC}_{2} \mathrm{O}_{4} \cdot 2 \mathrm{H}_{2} \mathrm{O}$ in linseed oil. The diffractograms of the various zinc oxalate concentrations show that concentrations below $0.5 \%$ (w/w) become difficult to observe with PXRD.

As indicated by the arrows in the close-up diffractogram in Fig. 6, weak crystalline zinc oxalate reflections were detected. These results suggest that the formed zinc oxalate is mostly present in an amorphous state, while only a minor fraction is crystalline.

\section{$\mu$-PXRD characterization}

As the presence of zinc oxalate was clear on both the surface and backside of the oil film judged by ATR-FTIR (Fig. 3a), and since bulk PXRD indicates that the zinc oxalate formed is mostly present in an amorphous state,

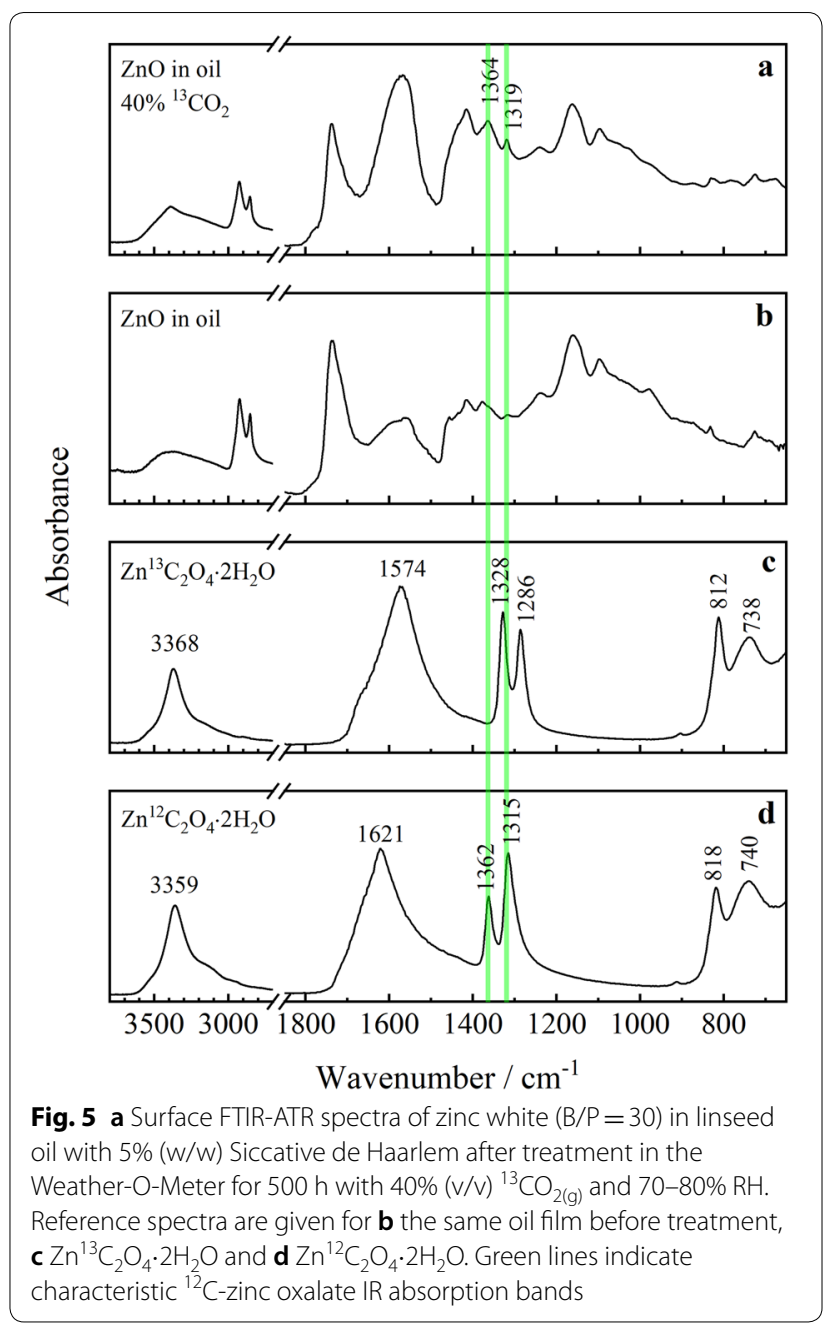

the zinc oxalate formation was further investigated by $\mu$-PXRD.

Comparing diffraction data from the exposed top surface (Fig. 7b) and bottom side (Fig. 7c) of the $\mathrm{ZnO}$ paint film, showed that the minor amount of crystalline zinc oxalate is present only at the exposed side and is absent on the bottom side, even though IR revealed oxalate vibrations bands with similar intensity on both sides of the paint film. The broad bands at $18.0^{\circ}, 22.6^{\circ}$ and $26.0^{\circ}$ $2 \theta$ in Fig. 7c originate from the Melinex foil. Regarding the $\mathrm{ZnO}$ film aged with the Weather-O-Meter and $40 \%$ $(\mathrm{v} / \mathrm{v}){ }^{13} \mathrm{CO}_{2(\mathrm{~g})}$ no indication of crystalline zinc oxalates was found (Fig. 7a).

Next to $\mathrm{ZnO}$ and $\mathrm{ZnC}_{2} \mathrm{O}_{4} \cdot 2 \mathrm{H}_{2} \mathrm{O}$, the diffraction signals marked $\nabla$ are present in all measurements (Fig. $7 \mathrm{a}-\mathrm{c}$ ). This species is best explained by a hydrated $\mathrm{Zn}$ carbonate hydroxide with chemical formula, $\mathrm{Zn}_{4}\left(\mathrm{CO}_{3}\right)(\mathrm{OH})_{6} \cdot \mathrm{H}_{2} \mathrm{O}$ (PDF-2 entry number 00-011-0287). These diffraction signals are due to an impurity in the $\mathrm{ZnO}$ powder (verified with XRPD). 

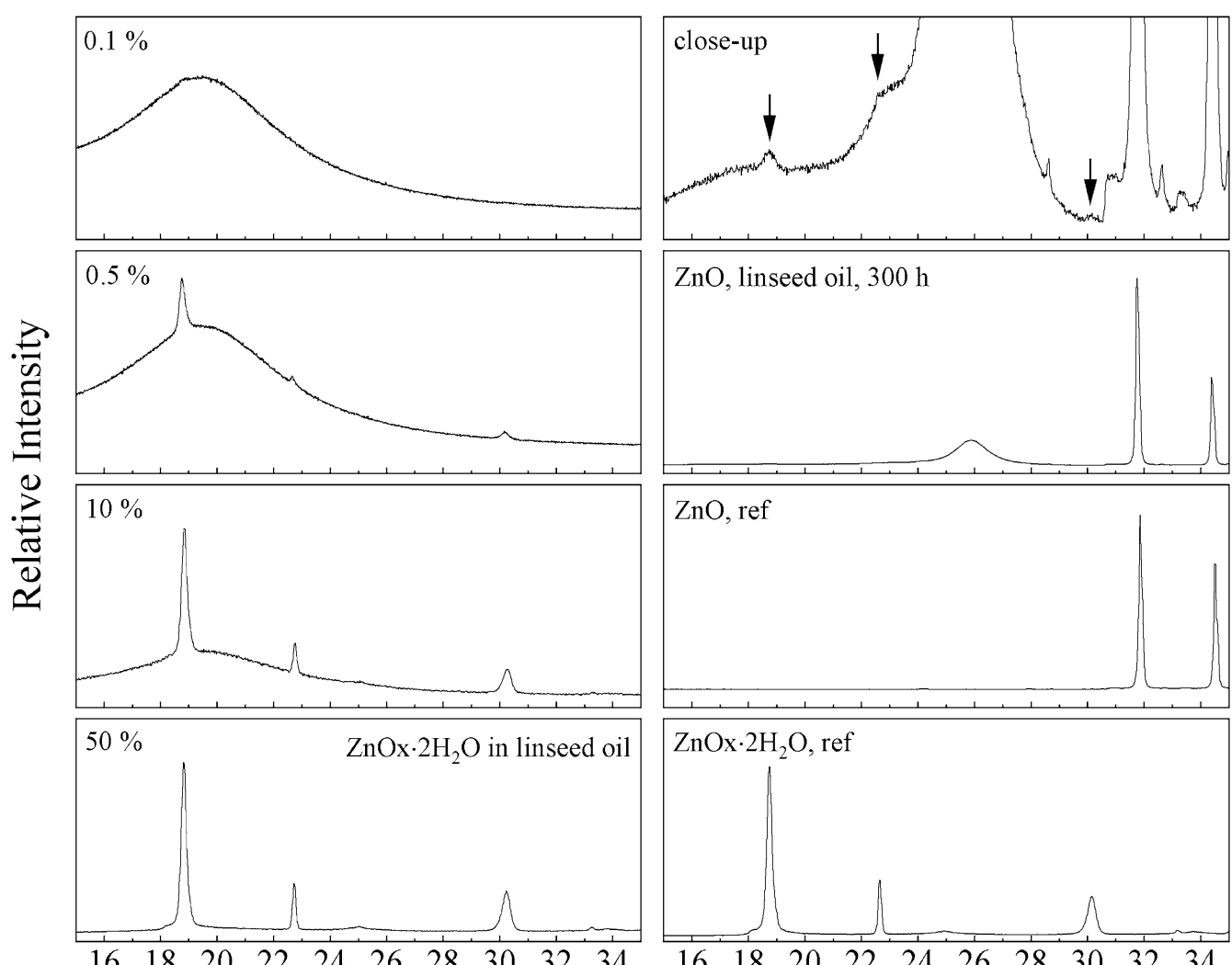

\section{$2 \theta /$ degrees}

Fig. 6 Left column: PXRD diffractograms of varying \% (w/w) amounts of zinc oxalate dispersed in linseed oil with $5 \%$ (w/w) Siccative de Haarlem. Right column: PXRD diffractograms of $\mathrm{ZnC}_{2} \mathrm{O}_{4} \cdot 2 \mathrm{H}_{2} \mathrm{O}, \mathrm{ZnO}$ and $\mathrm{ZnO}$ in linseed oil $(\mathrm{B} / \mathrm{P}=30)$ after treatment in the Weather-O-Meter for $300 \mathrm{~h}$ and $\mathrm{RH}=80 \%$. A close-up of the latter diffractogram is also shown, with arrows indicating characteristic zinc oxalate reflections

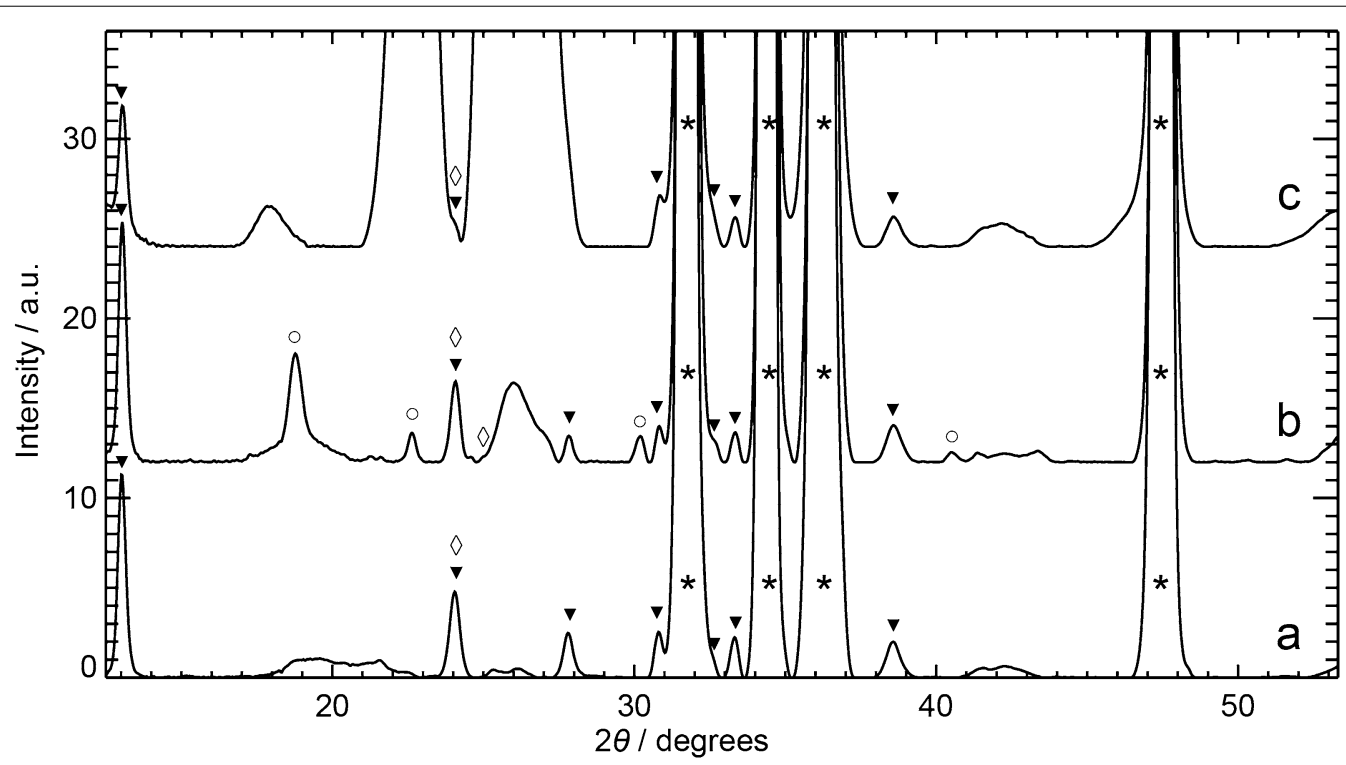

Fig. 7 PXRD patterns of $\mathrm{ZnO}$ in linseed oil $(\mathrm{B} / \mathrm{P}=30)$ after treatment in Weather-O-Meter for: (a) $500 \mathrm{~h}$ with $40 \%(\mathrm{v} / \mathrm{v}){ }^{13} \mathrm{CO}_{2(\mathrm{~g})}$ and $\mathrm{RH}=70-80 \%$; $(\mathrm{b})$ $300 \mathrm{~h}$ and $\mathrm{RH}=80 \%$ measured from the top side; and (c) measured from the bottom side. Legend: asterisk $=\mathrm{ZnO}$; open circle $=\mathrm{ZnC}_{2} \mathrm{O}_{4} \cdot 2 \mathrm{H}_{2} \mathrm{O} ; \mathrm{open}$ diamond $=\mathrm{ZnC}_{2} \mathrm{O}_{4}$; black down triangle $=\mathrm{Zn}_{4}\left(\mathrm{CO}_{3}\right)(\mathrm{OH})_{6} \cdot \mathrm{H}_{2} \mathrm{O}$ 
Characteristic IR vibrations for this compound [39] have also been detected in the IR spectra of the corresponding samples. It is worth mentioning that the diffraction signal of $\mathrm{Zn}_{4}\left(\mathrm{CO}_{3}\right)(\mathrm{OH})_{6} \cdot \mathrm{H}_{2} \mathrm{O}$ around $2 \theta=24^{\circ}$ could hide the presence of anhydrous $\mathrm{ZnC}_{2} \mathrm{O}_{4}$. Nonetheless, the presence of the latter seems unlikely, given the ageing conditions that were employed.

\section{Conclusions}

This paper has investigated the formation of metal oxalates by reaction of different pigments in linseed oil paint films under the influence of UVA light and humidity. The pigments investigated were zinc white $(\mathrm{ZnO})$, calcite $\left(\mathrm{CaCO}_{3}\right)$, lead white, $\left(\mathrm{Pb}_{3}\left(\mathrm{CO}_{3}\right)_{2}(\mathrm{OH})_{2}\right)$, zinc yellow $\left(\mathrm{KZn}_{2}\left(\mathrm{CrO}_{4}\right)_{2}\left(\mathrm{H}_{2} \mathrm{O}\right)(\mathrm{OH})\right)$, chrome yellow $\left(\mathrm{PbCrO}_{4}\right)$, cadmium yellow $(\mathrm{CdS})$, cobalt violet $\left(\mathrm{Co}_{3}\left(\mathrm{PO}_{4}\right)_{2}\right)$ and verdigris, $\left(\mathrm{Cu}\left(\mathrm{CH}_{3} \mathrm{COO}\right)_{2} \cdot \mathrm{H}_{2} \mathrm{O}\right)$. The UVA light-ageing experiment showed that linseed oil film with zinc white was particularly prone to metal oxalate formation, and that high humidity is a necessary requirement for the formation of metal oxalates.

Metal oxalate formation of $\mathrm{ZnO}$ was investigated further in different oil binding media under the influence of artificial sunlight and humidity. The different oil binding media were raw linseed with and without Siccative de Haarlem, standoil, and tall oil modified alkyd. Also standoil mixed with dammar, shellac, or pine colophony were investigated. Obtained results show that zinc oxalate was formed in all cases.

The influence of atmospheric carbon dioxide on the formation of zinc oxalate was also investigated by the use of ${ }^{13} \mathrm{C}$ labelled $\mathrm{CO}_{2(\mathrm{~g})}$. As the vibration bands of the resulting zinc oxalate appear at the frequencies for ${ }^{12} \mathrm{C}$-containing oxalate ion, and since the amount of zinc oxalate formed did not increase by increasing $\mathrm{CO}_{2(\mathrm{~g})}$ concentration, we consider it unlikely that atmospheric carbon dioxide plays a role in oxalate formation. It therefore supports the hypothesis that oxalate anion formation is due to the oxidation of the oil binder and not to the reduction of $\mathrm{CO}_{2}$. Moreover, our results seem to indicate a correlation between the formation mechanism of zinc oxalates and that of zinc soaps. However, further research is needed to clarify the possible link between both mechanisms.

In all cases, the zinc oxalate formed is mostly in an amorphous state; the presence of crystalline $\mathrm{ZnC}_{2} \mathrm{O}_{4} \cdot 2 \mathrm{H}_{2} \mathrm{O}$ could only be observed in minor amounts in the PXRD patterns, which are dominated by $\mathrm{ZnO}$ in the oil paint film. The formation of crystalline $\mathrm{ZnC}_{2} \mathrm{O}_{4} \cdot 2 \mathrm{H}_{2} \mathrm{O}$ is further limited to the light-exposed (top) side of the paint films.

\section{Supplementary information}

Supplementary information accompanies this paper at https://doi. org/10.1186/s40494-020-00467-z.

Additional file 1. Fig. S1. FTIR-ATR spectra of chrome yellow and zinc white in linseed oil with 5\%(w/w) Siccative de Haarlem. For each pigment, the top spectrum was obtained after treatment with UVA for $726 \mathrm{~h}$ and placement in desiccator filled with water for $1080 \mathrm{~h}$. Reference spectra of the oil film before treatment (middle) and of the relevant metal oxalates (bottom) are also shown. The B/P ratios are given in Table 1 (see article text)

\section{Acknowledgements}

Not applicable.

\section{Authors' contributions}

All authors contributed to data interpretation and to finalizing the manuscript. All authors have read and approved the final manuscript.

\section{Funding}

F. Vanmeert, K. Janssens, J. Sanyova and F. Mederos-Henry would like to thank The Belgian Science Policy (Belspo) of the Belgian Federal government for funding the "MetOx" Brain project (BR/165/A6/METOX).

\section{Availability of data and materials}

The datasets used and/or analysed during the current study are available from the corresponding author on reasonable request.

\section{Competing interests}

The authors declare that they have no competing interests.

\section{Author details}

${ }^{1}$ School of Conservation, Esplanaden 34, 1263 Copenhagen K, Denmark.

${ }^{2}$ AXES, Department of Physics, University of Antwerp, Groenenborgerlaan 171, 2020 Antwerp, Belgium. ${ }^{3}$ Laboratories of the Royal Institute for Cultural Heritage (KIK-IRPA), Parc du Cinquantenaire 1, 1000 Brussels, Belgium. ${ }^{4}$ Department of Chemistry, University of Copenhagen, Universitetsparken 5, 2100 Copenhagen $\varnothing$, Denmark.

Received: 1 October 2020 Accepted: 13 November 2020

Published online: 07 December 2020

\section{References}

1. Salvadó N, Butí S, Nicholson J, Emerich H, Labrador A, Pradell T. Identification of reaction compounds in micrometric layers from gothic paintings using combined SR-XRD and SR-FTIR. Talanta. 2009;79:419-28.

2. Sotiropoulou S, Papliaka ZE, Vaccari L. Micro FTIR imaging for the investigation of deteriorated organic binders in wall painting stratigraphies of different techniques and periods. Microchem J. 2016;124:559-67.

3. Monico L, Rosi F, Miliani C, Daveri A, Brunetti BG. Non-invasive identification of metal-oxalate complexes on polychrome artwork surfaces by reflection mid-infrared spectroscopy. Spectrochim Acta Part A Mol Biomol Spectrosc. 2013;116:270-80.

4. Otero V, Vilarigues M, Carlyle L, Cotte M, De NolfW, Melo MJ. A little key to oxalate formation in oil paints: protective patina or chemical reactor? Photochem Photobiol Sci. 2018;17:266-70.

5. Poli T, Piccirillo A, Zoccali A, Conti C, Nervo M, Chiantore O. The role of zinc white pigment on the degradation of shellac resin in artworks. Polym Degrad Stab. 2014;102:138-44.

6. Poli T, Piccirillo A, Nervo M, Chiantore O. Interactions of natural resins and pigments in works of art. J Colloid Interface Sci. 2017;503:1-9.

7. Unković N, Erić S, Šarić K, Stupar M, Savković Ž, Stanković S, Stanojević O, Dimkić I, Vukojević J, Grbić ML. Biogenesis of secondary mycogenic minerals related to wall paintings deterioration process. Micron. 2017;100:1-9. 
8. Castro K, Sarmiento A, Maguregui M, Martínez-Arkarazo I, Etxebarria N, Angulo M, Barrutia MU, González-Cembellín JM, Madariaga JM. Multianalytical approach to the analysis of English polychromed alabaster sculptures: $\mu R a m a n, \mu E D X R F$, and FTIR spectroscopies. Anal Bioanal Chem. 2008;392:755-63.

9. Castro K, Sarmiento A, Martínez-Arkarazo I, Madariaga JM, Fernández LA. Green copper pigments biodegradation in cultural heritage: from malachite to moolooite, thermodynamic modeling, X-ray fluorescence, and Raman evidence. Anal Chem. 2008:80:4103-10.

10. Rosado T, Gil M, Mirão J, Candeias A, Caldeira AT. Oxalate biofilm formation in mural paintings due to microorganisms - a comprehensive study. Int Biodeterior Biodegrad. 2013;85:1-7.

11. Lazzarini L, Salvadori O. A reassessment of the formation of the patina called scialbatura. Stud Conserv. 1989;34:20-6.

12. Rampazzi L, Andreotti A, Bonaduce I, Colombini MP, Colombo C, Toniolo L. Analytical investigation of calcium oxalate films on marble monuments. Talanta. 2004;63:967-77.

13. Van der Snickt G, Janssens K, Dik J, De NolfW, Vanmeert F, Jaroszewicz J, Cotte M, Falkenberg G, Van der Loeff L. Combined use of synchrotron radiation based micro-X-ray fluorescence, micro-X-ray diffraction, micro-X-ray absorption near-edge, and micro-fourier transform infrared spectroscopies for revealing an alternative degradation pathway of the pigment cadmium yellow in a painting by Van Gogh. Anal Chem. 2012;84:10221-8.

14. Mass J, Sedlmair J, Patterson CS, Carson D, Buckley B, Hirschmugl C. SR-FTIR imaging of the altered cadmium sulfide yellow paints in Henri Matisse's Le Bonheur de vivre (1905-6) — examination of visually distinct degradation regions. Analyst. 2013;138:6032-43.

15. Bordignon F, Postorino P, Dore P, Tabasso ML. The formation of metal oxalates in the painted layers of a medieval polychrome on stone, as revealed by micro-Raman spectroscopy. Stud Conserv. 2008;53:158-69.

16. Colombini MP, Modugno F, Fuoco R, Tognazzi A. A GC-MS study on the deterioration of lipidic paint binders. Microchem J. 2002;73:175-85.

17. Klaassen L, Van der Snickt G, Legrand S, Higgitt C, Spring M, Vanmeert F, Rosi F, Brunetti BG, Postec M, Janssens K. Characterization and removal of a disfiguring oxalate crust on a large altarpiece by Hans Memling. In: Casadio F, Keune K, Noble P, Van Loon A, Hendriks E, Centeno SA, Osmond G, editors. Metal soaps in art—conservation \& research. Switzerland: Springer International Publishing AG; 2019. p. 263-82.

18. Rosi F, Cartechini L, Monico L, Gabrieli F, Vagnini M, Buti D, Doherty B, Anselmi C, Brunetti BG, Miliani C. Tracking metal oxalates and carboxylates on painting surfaces by non-invasive reflection Mid-FTIR spectroscopy. In: Casadio F, Keune K, Noble P, Van Loon A, Hendriks E, Centeno SA, Osmond G, editors. Metal soaps in art-conservation \& research. Switzerland: Springer International Publishing AG; 2019. p. 173-93.

19. Monico L, Janssens $K$, Hendriks E, Vanmeert F, Van der Snickt $G$, Cotte M, Falkenberg G, Brunetti BG, Miliani C. Evidence for degradation of the chrome yellows in Van Gogh's sunflowers: a study using noninvasive in situ methods and synchrotron-radiation-based X-ray techniques. Angew Chem Int Ed. 2015;54:13923-7.

20. Spring M, Higgitt C, Saunders D. Investigation of pigment-medium interaction processes in oil paint containing degraded smalt. Natl Gallery Tech Bull. 2005;26:56-70.

21. White JL, Baruch MF, Pander JE III, Hu Y, Fortmeyer IC, Park JE, Zhang T, Liao K, Gu J, Yan Y. Light-driven heterogeneous reduction of carbon dioxide: photocatalysts and photoelectrodes. Chem Rev. 2015;115:12888-935.

22. Pougin A, Dilla M, Strunk J. Identification and exclusion of intermediates of photocatalytic $\mathrm{CO}_{2}$ reduction on $\mathrm{TiO}_{2}$ under conditions of highest purity. Phys Chem Chem Phys. 2016;18:10809-17.

23. Simonsen KP, Christiansen MB, Vinum MG, Sanyova J, Bendix J. Single crystal X-ray structure of the artists' pigment zinc yellow. J Mol Struct. 2017;1141:322-7.
24. Hansen F, Jensen OI. Farvekemi: Uorganiske pigmenter. København: Gads Forlag; 1991.

25. De Nolf W, Vanmeert F, Janssens J. XRDUA: crystalline phase distribution maps by two-dimensional scanning and tomographic (micro) X-ray powder diffraction. J Appl Cryst. 2014:47:1107-17.

26. Altomare A, Corriero N, Cuocci C, Falcicchio A, Moliterni A, Rizzi R. QUALX2.0: a qualitative phase analysis software using the freely available database POW_COD. J Appl Cryst. 2015;48:598-603.

27. Grazulis S, Chateigner D, Downs RT, Yokochi AT, Quiros M, Lutterotti L, Manakova E, Butkus J, Moeck P, Le Bail A. Crystallography open database-an open-access collection of crystal structures. J Appl Cryst. 2009:42:726-9.

28. Otero V, Sanches D, Montagner C, Vilarigues M, Carlyle L, Lopes JA, Melo MJ. Characterisation of metal carboxylates by Raman and infrared spectroscopy in works of art. J Raman Spectrosc. 2014;45:1197-206.

29. Hermans JJ, Keune K, van Loon A, ledema PD. An infrared spectroscopic study of the nature of zinc carboxylates in oil paintings. J Anal At Spectrom. 2015;30:1600-8.

30. Christiansen MB, Sørensen MA, Sanyova J, Bendix J, Simonsen KP. Characterisation of the rare cadmium chromate pigment in a 19th century tube colour by Raman, FTIR, X-ray and EPR. Spectrochim Acta Part A Mol Biomol Spectrosc. 2017;175:208-14.

31. Monico L, Janssens K, Cotte M, Romani A, Sorace L, Grazia C, Brunetti BG, Miliani C. Synchrotron-based X-ray spectromicroscopy and electron paramagnetic resonance spectroscopy to investigate the redox properties of lead chromate pigments under the effect of visible light. J Anal At Spectrom. 2015;30:1500-10.

32. Chesunov VM, Vasenin RM. The kinetics of solvent evaporation during film formation from polymer solutions. Polym Sci (USSR). 1967:9:2333-8.

33. Clark RJH, Firth S. Raman, infrared and force field studies of $\mathrm{K}_{2}^{12} \mathrm{C}_{2} \mathrm{O}_{4} \cdot \mathrm{H}_{2} \mathrm{O}$ and $\mathrm{K}_{2}^{13} \mathrm{C}_{2} \mathrm{O}_{4} \cdot \mathrm{H}_{2} \mathrm{O}$ in the solid state and in aqueous solution, and of $\left(\mathrm{NH}_{4}\right)_{2}^{12} \mathrm{C}_{2} \mathrm{O}_{4} \cdot \mathrm{H}_{2} \mathrm{O}$ and $\left(\mathrm{NH}_{4}\right)_{2}^{13} \mathrm{C}_{2} \mathrm{O}_{4} \cdot \mathrm{H}_{2} \mathrm{O}$ in the solid state. Spectrochim Acta A. 2002;58:1731-46.

34. Hermans JJ, Keune K, van Loon A, Corkery RW, ledema PD. lonomer-like structure in mature oil paint binding media. RSC Adv. 2016;6:93363-9.

35. Baij L, Hermans JJ, Keune K, ledema P. Time-dependent ATR-FTIR spectroscopic studies on fatty acid diffusion and the formation of metal soaps in oil paint model systems. Angew Chem Int Ed. 2018;57:7351-4.

36. Baij L, Hermans JJ, Keune K, ledema PD. Time-dependent ATR-FTIR spectroscopic studies on solvent diffusion and film swelling in oil paint model systems. Macromolecules. 2018;51:7134-44.

37. Hermans J, Osmond G, van Loon A, ledema P, Chapman R, Drennan J, Jack K, Rasch R, Morgan G, Zhang Z. Electron microscopy imaging of zinc soaps nucleation in oil paint. Microsc Microanal. 2018;24:318-22.

38. Hermans JJ, Baij L, Koenis M, Keune K, ledema PD, Woutersen S. 2D-IR spectroscopy for oil paint conservation: elucidating the watersensitive structure of zinc carboxylate clusters in ionomers. Sci Adv. 2019;5:eaaw3592.

39. Levine KE, Collins BJ, Stout MD, Wyde M, Afton SE, Essader AS, Ennis TJ, Amato KE, MCWilliams AC, Fletcher BL, Fernando RA, Harrington JM, Catlin N, Robinson VG, Waidyanatha S. Characterization of zinc carbonate basic as a source of zinc in a rodent study investigating the effects of dietary deficiency or excess. Anal Lett. 2017:50:2447-64.

\section{Publisher's Note}

Springer Nature remains neutral with regard to jurisdictional claims in published maps and institutional affiliations. 